DE ECONOMIST 158, NO. 1, 2010

\title{
MARKET SHARE AND PRICE IN DUTCH HOME CARE: MARKET POWER OR QUALITY?
}

BY

ILARIA MOSCA*,**, MARC POMP*** AND VICTORIA SHESTALOVA****

\section{Summary}

The paper uses unique data on contracts concluded by providers of home care to evaluate the effect of provider market power on prices of home care services in the Netherlands. Since, at least in some regions, one or two providers dominate the market, there are concerns about the effect of providers' market power on the pricing of home care services. Using data on contracted prices and quantities for 2004-2006, we find that providers with a larger market share are able to contract at a higher price. The effect remains after controlling for quality.

Key words: home care, selective contracting, market structure, quality

JEL Code(s): D4, I11, I18

\section{INTRODUCTION}

Worldwide ageing societies and the increase in chronic illnesses are leading to a growing demand for long-term care, which puts long-term care on the list of priorities that need to be addressed by public policies (WHO 2003). Since the beginning of the new century, the cost of long-term care have ballooned in all European countries and is projected to grow exponentially in the future. These trends cause concerns about the affordability and sustainability of the whole system of service provision (WHO 2008) and call for finding more efficient ways of organizing and delivering long-term care.

Traditionally, public policies in this field have been focused on institutional ('residential') care at nursing homes, as these were the main suppliers of these services. However, lately there has been a substantial increase in the use of long-term care delivered in the home care setting. The two primary features of home care services are: first, the individual remains in his home

* Corresponding author: Ilaria Mosca, Tilburg University, Tilburg Law and Economics Centre (TILEC), P.O. Box 90153, 5000 LE Tilburg, The Netherlands, e-mail: i.mosca@uvt.nl

** Dutch Healthcare Authority, Utrecht, The Netherlands

*** Marc Pomp Economic Policy Analysis, Breda, The Netherlands

**** Netherlands Bureau for Economic Analysis (CPB), The Hague, The Netherlands

The views expressed in this article are those of the author and do not represent the official policy or position of the Dutch Healthcare Authority. 
setting and is not institutionalized; second, care can be also given by family members and/or relatives. Important advantages of this type of care, especially for elderly individuals, are that this maintains independence and prevents deterioration into ill health. From a social point of view, the substitution of home care for residential care has the additional advantage that costs are often lower.

The process of substitution of home care for residential care coincides with market-based health care reforms in many countries. These institutional changes unveil new policy issues concerning the effectiveness of market mechanisms in different segments of health care, which represent challenges both for policymakers and academic researchers. One of the market mechanisms introduced by the reforms in different segments of health care is selective contracting. The empirical literature on this topic is very small (see Section 2) and has been mainly centered around hospital care. However, the growing importance of long term-care, particularly home care, leads to the need of extending this research to this segment, which is organized and financed rather differently from hospital care (see Section 3).

This paper complements the existing literature by providing new insights about potential effects of selective contracting in the home care setting and related policy issues. The focus is on the Dutch home care market. The Netherlands is an interesting case to analyze given that this country is undergoing a large scale reform in its health care policy resulting in a new demand-driven and market-oriented health care delivery system. The reform of the long-term care industry in the Netherlands has begun with a change of legislation in 2004 of the Dutch Exceptional Medical Expense Act (EMEA) that allowed for more competition among suppliers of home care services. More precisely, the new law made it possible for the 32 regional health care purchasing agencies spread in the country to contract suppliers selectively and negotiate over prices and quality. Selective contracting could create incentives for providers to offer better services. Thus, the new law created something akin to the internal market in the British National Health Service in the 1990s.

Although the change in legislation was meant to create incentives to negotiate home care services at lower prices, it only achieved a minor improvement compared to the previous situation. The outcome of negotiations is often at the regulatory maximum price or very close to it (about $30 \%$ of our sample), and there are large prices differences across providers. In this paper we analyze two major factors that may explain these price differences: provider market power and quality.

Market power is a serious concern in the home care market. At least in some regions, one or two large providers dominate the regional market and there is ongoing concentration among providers in other regions. Large providers may be able to exercise market power in negotiation with the purchasing agencies responsible for contracting care, which produces a pos- 
itive relationship between market share and the resulting price. However, a high market share and a high price can both be the result of high quality. It may be purchasing agencies use their bargaining power to induce higher quality rather than to lower the price (competition on quality). Therefore, we include quality in the regressions to control for this effect. The result that market share increases price is robust to the inclusion of quality.

The paper is structured as follows. In Section 2 we will review the literature on market structure and health care market. We will then explain the Dutch institutional setting and market set-up in the provision of home care services (Section 3). Next, we describe the data and the trends in the development of this sector (Section 4), after which we turn to the empirical analysis (Section 5). Section 6 concludes.

\section{LITERATURE REVIEW}

The empirical literature that studies the effect of selective contracting on pricing by health care providers is very small and consists mainly of studies on the US. These studies focus primarily on the effect of market indicators (the number of firms or concentration indices) and firm-related indicators (ownership structure and market share) on prices in contracts concluded between insurers and hospitals. These papers test the hypothesis that market players with relatively stronger market position (i.e. more market power) obtain better deals. More precisely: they test the hypotheses that a larger market share, or less competition, or both these factors lead to a more favorable price for the firm. ${ }^{1}$

The empirical results mostly confirm the hypothesis that a lower degree of market competitiveness (e.g. higher concentration) creates a price advantage for firms in this market. However, it appears that larger market share does not always enable the firm to exercise market power (Staten et al. 1987, 1988). Staten et al. (1988) evaluated the effects of the market structure of the hospital market and insurer market share on the discounts offered by hospitals to gain acceptance into the Blue Cross PPO in Indiana and found that the discount was positively related to the number of competing hospitals (as one would expect), but negatively related to the Blue Cross share of hospital revenue. Since the analysis of Staten focused on the period when Blue Cross just made the transition into a PPO plan, Melnick et al. (1992) attributed the

1 In particular, more market power of an insurer leads to a larger discount, and more market power of a provider leads to a higher price for its health care services. The upward effect of provider market power on prices is stressed also in the theoretical literature. Gal-Or (1999) argues that the desire to strengthen bargaining power may be also an important driving factor behind the on-going integration of physician and hospitals. 
second result to the relative inexperience with selective contracting of the newly formed Blue Cross Indiana PPO.

Bamezai et al. (2003), who used a probit model to analyze the contracting data of California's Medicaid program (Medi-Cal), found no evidence in favor of the hypothesis that a large payer (the insurer) was better able to exercise market power, while they found a significant effect of the number of competitors in the hospital market. In particular, hospitals with fewer competitors had greater bargaining power vis-à-vis Medi-Cal and were less likely to negotiate a contract.

Brooks et al. (1997) support the hypothesis that a larger size enables an insurer to get better deals from hospitals, but not the hypothesis that a larger size of a hospital enables it to get better deals from insurers. In particular, contrary to Staten et al. (1988), this paper found that insurers with a greater presence in the market have a greater bargaining power. On the hospital side, however, a marginally significant negative relationship between the size of the hospital and hospital bargaining power was found. The authors derive their empirical model from a theoretical bargaining model of Svejnar (1986) and estimate it by Ordinary Least Squares (OLS). ${ }^{2}$ The estimate of the hospital bargaining power parameter reveals that hospitals have relatively more bargaining power than insurers. Additionally, greater hospital concentration improves the bargaining position of the hospital; and a greater enrolment of the population in HMOs has a positive impact on hospital bargaining power with respect to fee-for-service plans.

Significant effects of many market structure indicators have been found in the study of Melnick et al. (1992), which results lend support to the hypotheses expressed above. The authors investigate prices obtained in different types of markets by the largest PPO in California. They show that greater hospital competition leads to lower prices. Furthermore, as the importance of a hospital to the PPO in an area increases, the price rises substantially. Another significant result is that the higher the percentage a hospital's total patient days accounted for by Blue Cross, the greater the leverage Blue Cross has with the hospital. Per-diem prices negotiated between Blue Cross of California and providers are used to examine the effect of market structure on PPO prices and regressed using two-stage least squares (2SLS) on a vector of covariates, including both market and provider characteristics. The estimated coefficient for the HHI, that varies between 0.11 and 0.13 and is highly significant, shows that, after controlling for product differences, Blue Cross pays higher prices to hospitals located in less competitive markets. The authors also test alternative methods to define hospital geographic markets and reveal that the

2 Given the censored nature of the dependent variable in this study, Halbersma et al. (2007) suggest that using a more advanced estimation procedure for censored data would increase the consistency of estimates. 
common practice of using counties to define the market leads to an underestimation of the price-increasing effects of a merger.

Although the literature generally confirms that market circumstances affect the outcome of contracting, it also shows that the relative importance (significance) of these factors may differ across markets. In particular, the effect of market share on prices varies and may be highly sensitive to the institutional setting. Note also that most of the literature concerns the hospital industry. With the penetration of selective contracting practices in other segments of health care, such as nursing care and home care, the same question needs to be answered also for these new markets.

\section{HOME CARE IN THE NETHERLANDS}

The Dutch Exceptional Medical Expense Act (EMEA) came into force in the Netherlands in 1968. This insurance scheme covers the whole population for long-term care, mental illness requiring prolonged nursing and care, and congenital physical or mental handicap. The target group for services provided under the Act has expanded a great deal and has become much more diverse over the past few years; it presently mainly comprises elderly people, the disabled and mentally ill patients with chronic problems. Each individual is automatically insured for EMEA services; contribution depends on income and is levied by the tax authorities. EMEA services also demand outof-pocket outlays of the user, which can be quite substantial.

\subsection{Organization of the Home Care Provision Under EMEA}

The EMEA insurance delivers both residential (inpatient) services and home (outpatient) services. The main differences between residential and home care are the following:

- Residential services are delivered inside a medical institution, such as a nursing home, psychiatric clinic, etc. Residential care involves more investment (e.g. in the infrastructure), it needs an extra license for expanding the range of services, economies of scale are likely to arise, and only nonprofit institutions deliver care.

- Home care relates to all services provided to patients living outside a medical institution. It does not involve a specific investment in expensive infrastructure, an expansion of a service (function of care) ${ }^{3}$ can be arranged quicker and easier than residential care because there is no need

3 The products that are included in our dataset can be allocated into the following functions of care: house care, personal care, nursing, general supervision, activating supervision, and treatments. Please refer to Appendix 1 for a brief description of the above-mentioned functions of care. 
for an extra license, there is a high concentration of firms in the market, and since January 2006 for-profit firms are allowed to enter the market. ${ }^{4}$

We focus on home care. There are currently 800,000 people in the Netherlands eligible for these services. A special institution ${ }^{5}$ assesses the amount of home care needed by each of these individuals. In each region of the Netherlands, a single purchasing agency is in charge of buying the necessary amount of home care for this region. ${ }^{6}$ These agencies thus act as monopsonists in the region. They are responsible for contracting care to satisfy the needs of the region. By means of their purchasing and contracting policies, purchasing agencies effectively set the amount and quality of the care contracted. ${ }^{7}$ Figure 1 presents the division of the Netherlands in 32 home care regions.

Providers of home care must have a legal permit to supply their services. ${ }^{8}$ Home care providers bargain with purchasing agencies over the amounts and the prices of care to be delivered. Contracts are negotiated on a yearly basis. Negotiations take place with the purchasing agency of the region in which the supplier is officially registered. In the last few years the Dutch home care sector experienced several changes, which aimed to introduce market competition elements into the system. In particular, Dutch purchasing agencies have been allowed to contract providers selectively and to set different requirements for different suppliers (CTG/ZAio and CTZ 2005). ${ }^{9}$

4 See NZa (2006).

5 This Institution is called in Dutch Centrum Indicatiestelling Zorg, CIZ.

6 It is also possible for suppliers to provide services to clients residing outside the purchasing agency's own region. If $35 \%$ or more of all clients of a supplier come from a different region than the one where the supplier is officially registered, the purchasing offices of the concerned regions are jointly responsible for contracting such a provider, and they consult with each other about the financing of care. If $85 \%$ or more of all clients of a supplier come from another region, purchasing agencies can decide to delegate negotiations with the supplier to the purchasing agency of the region where the majority of its clients is situated (CTG/ZAio and CTZ 2005).

7 Purchasing agencies must inquire the clients' experiences concerning the health services they received. Therefore they observe at least some dimensions of quality and thus can use this information when selecting among regional providers.

There are more arrangements safeguarding the level of quality of home care in the Netherlands. A specific law on quality makes the provider of EMEA services responsible for their own quality levels (ICM 2005). The Inspectorate for Health care (IGZ) checks whether each supplier complies with the minimum quality requirements set by law.

8 This permission is released by the Centraal Informatiepunt Beroepen Gezondheidszorg, CIBG.

9 The other notable changes are providing the possibility for clients to opt for a personal budget with which to buy care, defining functions of care to tailor consumers' demands, and enabling providers to defray their costs based on these functions. Moreover, in 2007 the function 'house care' (see Appendix 1) has been transferred to the municipalities. 


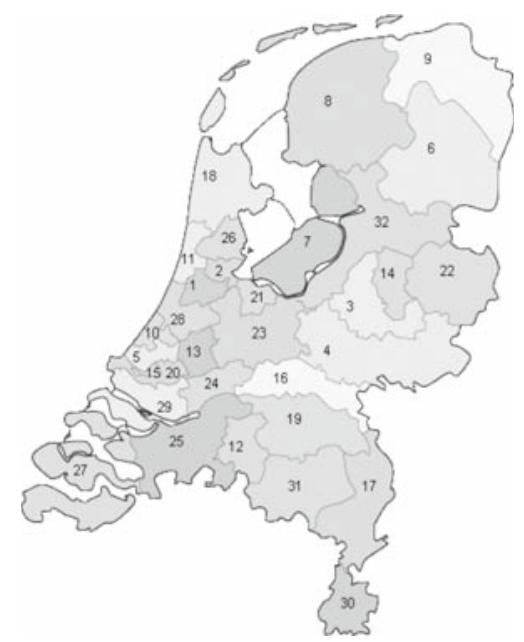

Figure 1 - EMEA regions in the Netherlands, Source: Zorgverzekeraars Nederland (2006)

\subsection{Funding}

Funding of EMEA services consists of two parts: (i) purchasing agencies are reimbursed for the care services delivered by their contracted providers; (ii) they receive a fixed budget set by the Ministry to cover their own operation cost. Typically, the health insurance company with the highest market share in a region performs the role of the purchasing agency in that region. ${ }^{10}$ The insurer is not at risk for the cost of home care delivered by contracted providers. Instead, these costs are paid out of a special fund for EMEA services, which is filled by premiums paid by the employed and all tax payers who have income from labor or home ownership. ${ }^{11}$ Insurers are only at risk with respect to the second part of the funding - the operation cost, since the insurer bears any excesses or shortfalls between actual operation costs and the budget. This structure creates an incentive for an insurance company to control the operation costs of its purchasing agency (NMa 2004).

Until 2004, there were no restrictions on the total budget of each health care purchasing agency. Therefore, the volume of care they could contract in those years was unrestricted. However, since 2004, the budget room available for contracting has been capped, restricting in turn also the total volume of care that could be contracted. This produced a change in incentives of health purchasing agencies, affecting both quantities and prices.

10 Some insurance companies have a high market share in more than one region. These companies have therefore control of purchasing agencies in different regions.

11 This budget is called Algemene Fonds Bijzondere Ziektekosten, AFBZ. 
The social responsibility of purchasing agencies should stimulate them to act in the best interests of consumers. The budgetary caps make them more aware of health care costs, which should create incentive to select better providers and achieve better deals. Yet, the incentive to reduce the price of contracted care is weakened to the extent that more intensive bargaining with suppliers over prices of services involves higher operation costs. The pressure to fulfill their contracting obligations at lower operation costs creates the incentive to select larger providers. Besides, the agency would always strive for concluding contracts with all the major regional providers because failing to conclude a contract with such providers would cast a negative image on the agency and the insurer (NZa 2007), affecting the insurer's position in the market for health insurance. Therefore, health care providers know they will get a deal with the purchasing agency and have thus no incentives to reduce the price.

\section{DATA}

The dataset used in this paper contains data on contracted prices and quantities of home care services in the Netherlands and covers the period 2004 $2006 .{ }^{12}$ It contains data on 1,403 service providers. There exist in total 121 different services, however, a particular provider typically provides fewer services. There are 32 regional health care purchasing agencies. The contracted prices and quantities result from negotiation between providers and purchasing agencies, in which each provider negotiates its tariffs and quantities with only one such agency. Contracted prices cannot exceed maximum tariffs, set by the Dutch Healthcare Authority (NZa) at the national level. The maximum tariff for each product is also included in our dataset.

Home care services can be divided into two large segments, to which we refer as $\mathrm{H}$ and $\mathrm{F}$ in accordance with their official coding by the NZa. ${ }^{13}$ The $\mathrm{H}$-segment includes what we call 'home care': house cleaning and personal care, supporting and activating supervision, and nursing. The F-segment covers products that relate to mental health. Table 1 compares the contracted prices and the regulatory maximum tariffs. Although there is a small downward trend in the ratio of contracted prices to regulated prices as well as a decline in the share of observations featuring maximum prices, there are still about $30 \%$ of such observations. The average contracted price is $6 \%$

12 This excludes unreliable observations (those with missing and negative values as well as the observations for one product where the data were not expressed in the same units for each years). The data were also available for 2003, however, data on 2003 are not fully consistent with the rest of the sample, therefore we could not use them.

13 The coding of products is in accordance with Circular CA-92. 
TABLE 1 - COMPARISON OF CONTRACTED PRICES TO REGULATED MAXIMUM TARIFFS

\begin{tabular}{lccc}
\hline & 2004 & 2005 & 2006 \\
\hline $\begin{array}{l}\text { Contracted prices as a percentage of regulated maximum tariffs (means with } \\
\text { standard deviations in brackets) }\end{array}$ & \multicolumn{2}{c}{$95 \%(7)$} \\
H-segment & $97 \%(7)$ & $95 \%(8)$ & $89 \%(5)$ \\
F-segment & $90 \%(6)$ & $89 \%(6)$ & $94 \%(7)$ \\
Overall & $95 \%(8)$ & $94 \%(8)$ & $34 \%$ \\
Percentage of observations with contracted prices equal to maximum tariffs \\
H-segment & $71 \%$ & $38 \%$ & $2 \%$ \\
F-segment & $10 \%$ & $7 \%$ & $26 \%$ \\
Overall & $54 \%$ & $29 \%$ & \\
\hline
\end{tabular}

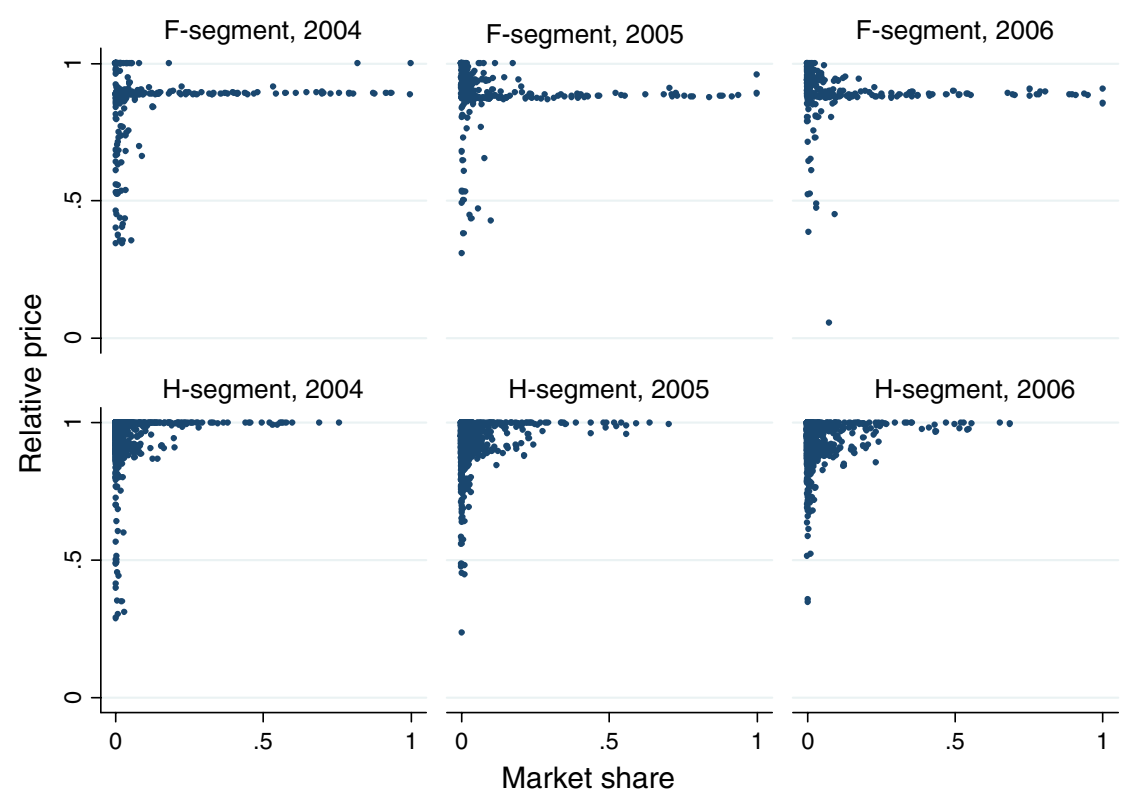

Figure 2 - Relation between market share and relative price (relative price is defined as the ratio of contracted price to regulated maximum tariff)

below the maximum, the standard deviation being 7\%. Figure 2, reflecting the relation between market share and the level of price, reveals more detail on price differences across providers in both segments. We observe that in the 
H-segment, contracted prices of large providers are close to the regulatory maximum price. $^{14}$

Since with just a few exceptions, providers normally specialize in delivering either $\mathrm{H}$ - or F-products, it is possible to analyze the H-segment (conventional home care) separately from the other segment. The analysis of the F-segment would be more problematic, because there the service area of a provider often overlaps with other regions. Providers operating in the F-segment often deliver services to more than one region, causing problems in defining regional markets (PWC 2005). Therefore, in the next section, we focus purely on the H-segment and include only providers from this segment, thus excluding providers that traditionally specialize on services to patients with mental illness or congenital physical or mental handicap.

\section{ESTIMATION}

In line with other empirical papers that focus on the effect of the market structure on price (discussed in Section 2), we assume that the prices of each provider depend on structural characteristics (provider market share and market concentration), other provider characteristics, and characteristics of the regional agency. We define these variables as follows.

Provider market share, $s$, is the share of its contracted production volumes (weighted by regulated maximum tariffs) in the total production volumes contracted by the regional agency. The use of contracted volumes, instead of realized volumes, allows us to avoid endogeneity. Since providers cannot adjust their production capacity (personnel) in the short run, the volumes offered for contracting are actually fixed in advance, so that the negotiation goes on price, rather than on quantity.

The degree of market concentration is expressed by the regional Hirschman-Herfindahl Index, HHI, defined for each region as $H H I=\sum s_{i}^{2}$, where $i$ runs over the set of all regional providers. The provider market share $s_{i}$ characterizes the relative market position of the provider, and $H H I$ relates to market conditions in general.

14 The fact that prices in this segment lie closer to the regulated values than those in the F-segment allows for different interpretations. It is likely that the regulator has better insight in the cost level in the H-segment than in the F-segment. In fact, the regulator uses the results of benchmarking analyses to set maximum prices in the H-segment, while such analyses are not available for the F-segment. However, the discrepancy may also arise for other reasons (e.g. related to quality). Additionally, as from January 1st, 2007 the function of 'house care' has passed under the jurisprudence of a new law (WMO, Wet Maatschappelijke Ondersteuning). This change brought uncertainty to health care providers because it was not explicit what would happen with their financial reserves. This might have influenced the contract relationship in 2006 between health care providers and purchasing agencies, namely purchasing agencies collaborated in fixing relatively high prices in order to avoid financial distress of providers in 2007. 


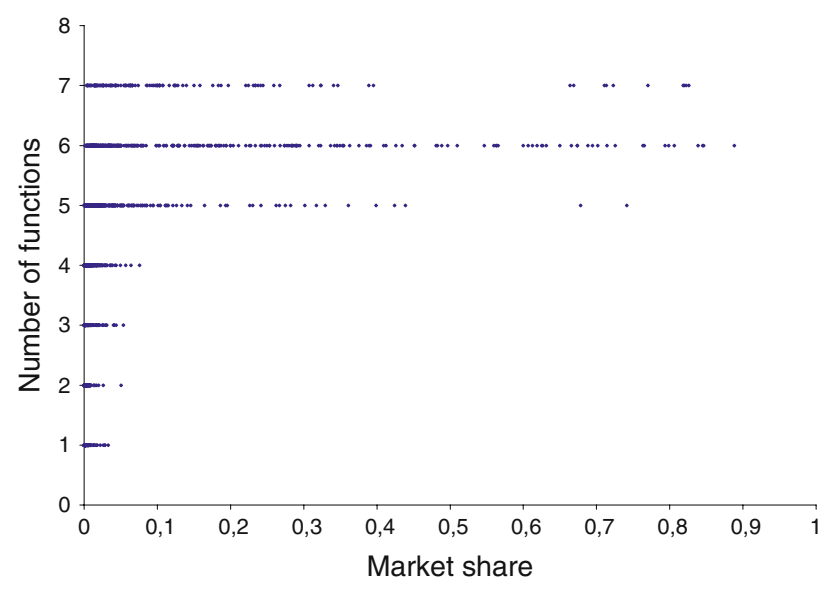

Figure 3 - Number of functions and market share, 2004-2006

An important provider characteristic that we include is the number of functions, $N$, performed by the provider. When defining the functions, we apply the same classification of allocation as used by the regulator (see Appendix 1). We expect the effect of this variable on price to be positive. First, agencies may prefer providers with a broader function range as these providers can combine services and serve also clients with broad range of needs. Second, if it is relatively more expensive to deliver services to clients who need a broader range of care, then providers with more functions should also demand a higher price. As can be seen from Figure 3, all large providers have at least four functions, while there are small providers with any number of functions.

Finally, we include regional dummies in order to control for the differences across regional agencies (on which we do not have much information), as well as year dummies.

Next to differences across regions, there may be also differences across providers within the same region. First, provider costs may differ due to differences in travel costs to reach clients (e.g., higher travel costs in rural areas where clients may be more disperse). Second, informal care and nursing homes represent alternatives to home care for some patients and may affect market conditions within regional markets. In order to explicitly account for these effects one would need to know the information on providers' locations within regions, which is not available to us. Note, however, that we do not have reasons to believe that there are systematic differences in these factors in favor of small providers, i.e., that on average small providers face more favorable market conditions or lower travel costs than large companies. Hence, we do not explicitly control for these factors in our regression. 
This leads to the followings specification of the empirical model:

$$
\begin{aligned}
p= & \beta_{0}+\beta_{S} s+\beta_{H H I} H H I+\beta_{N} N+\sum \beta_{\text {region }} D_{\text {region }} \\
& +\sum \beta_{\text {year }} D_{\text {year }}+\varepsilon
\end{aligned}
$$

The dependent variable $p$, reflecting the price level of the provider, is defined as a 'normalized price': the ratio of the revenue contracted by the provider (equal to the sum of contracted volumes multiplied by contracted prices) to its potential maximum revenue (equal to the sum of contracted volumes multiplied by regulatory maximum tariffs).

Since contracted prices are restricted by the regulated maximum tariffs, the dependent variable is restricted by 1 . OLS estimates would be biased in this case; therefore, we choose to use Tobit estimates for censored data. ${ }^{15}$

\subsection{Estimation of the Effect of Market Share}

Table 2 shows estimation results both including and excluding the variable 'number of functions' (see regressions 1 and 2). The results are in line with what we expected. They support the presence of a positive relationship between market share and price. The positive and highly significant coefficient for market share indicates that the price is an increasing function of market share in the relevant range.

The coefficient 0.134 in Regression 1 means that a market share increase of $1 \%$ translates into an increase of the relative price of $0.134 \%$. Table 3 illustrates the potential price differences as the result of the differences in market share, based on the results of our estimates in Table 2. According to these estimates large providers who serve half of the regional market are able to charge about $4 \%$ more than small providers (where not restricted by the regulated maximum tariffs).

In contrast to most studies reviewed in Section 2, the effect of HHI appears to be small and insignificant. This result holds even if we re-estimate the relationship excluding regional dummies or excluding market share $s$ (not shown here). Since the effect of HHI is insignificant and moreover has a negative

15 The standard Tobit regression assumes that the observations are independent. However, we have more than one observation on each provider in our dataset. Since such observations are not independent, we need to take care of this when estimating the variance-covariance matrix of the estimators. To do so, we used the cluster option of the intreg-estimator provided in Stata. The intreg-command obtains the same coefficients as a Tobit regression, but improves the robustness of the standard errors. The cluster option specifies that the standard errors allow for intragroup correlation, relaxing the usual requirement that the observations are independent. We clustered by provider so to specify that the observations are independent across groups but dependent within groups. The same approach has been used, e.g., by Burr et al. (2005). 
TABLE 2 - TOBIT-ESTIMATION OF THE EFFECT OF STRUCTURAL CHARACTERISTICS ON RELATIVE PRICE, 2004-2006

\begin{tabular}{|c|c|c|c|c|}
\hline & Regression 1 & $\begin{array}{l}\text { Regression } 2 \\
\text { (controlling for } \\
\text { complexity) }\end{array}$ & $\begin{array}{l}\text { Regression } 3 \\
\text { (adding } \\
\text { quality, } 2005 \\
\text { only) }\end{array}$ & $\begin{array}{l}\text { Regression } 4 \\
\text { (adding } \\
\text { quality, } \\
\text { assuming it } \\
\text { does not } \\
\text { change over } \\
\text { time) }\end{array}$ \\
\hline S & $0.134 * * *$ & $0.085^{* * *}$ & $0.062 * *$ & $0.055^{* * *}$ \\
\hline HHI & -0.028 & -0.013 & & -0.014 \\
\hline Number of functions & & $0.008 * * *$ & $0.009 * * *$ & $0.008 * * *$ \\
\hline Quality & & & 0.015 & 0.032 \\
\hline Missing quality dummy & & & 0.090 & 0.238 \\
\hline Year2 & $-0.043 * * *$ & $-0.044 * * *$ & & $-0.044 * * *$ \\
\hline Year3 & $-0.043^{* * *}$ & $-0.044 * * *$ & & $-0.044 * * *$ \\
\hline Const & $0.981 * * *$ & $0.949 * * *$ & $0.808 * * *$ & $0.711 * * *$ \\
\hline Number of observations & 2497 & 2497 & 843 & 2497 \\
\hline $\begin{array}{l}\text { Number of censored } \\
\text { observations }\end{array}$ & 517 & 517 & 99 & 517 \\
\hline LL & 1952 & 1986 & 823 & 1990 \\
\hline Chi2 & 387.4 & 399.4 & 185.3 & 411.3 \\
\hline Chi2 (regional dummies) & ${ }^{a} 154.2$ & 149.8 & 127.4 & 155.5 \\
\hline
\end{tabular}

Note: $* p<.1 ; * * p<.05 ; * * * p<.01$.

a Regional dummies were also included in regressions. Here we do not report the respective coefficients in order to safe space. Chi2 (regional dummies) corresponds to the test for their joint significance.

TABLE 3 - PRICE INCREASE AS THE RESULT OF CHANGE IN MARKET SHARE

Point increase in market share (\%)

Resulting price increase (regression 1) (\%)

Resulting price increase after correction for complexity (regression 2) $(\%)$

$\begin{array}{llll}5 & 25 & 45 & 65 \\ 0.7 & 3.4 & 6.0 & 8.7 \\ 0.4 & 2.1 & 3.8 & 5.5\end{array}$

sign, it is unlikely that the concentration itself is the reason for relatively high prices in some regions. Omitting HHI from the model (not shown here) does not produce much change to the other coefficients and their $t$-statistics. ${ }^{16}$

As expected, the effect of the number of functions on price is positive and significant. We also find significant differences in contracted prices for

16 The correlation between market share $s$ and HHI is 0.14 . 
some health care purchasing agencies. To the extent that market share picks up market power, this must reflect other factors than relative bargaining strength. The negative coefficients for the year-dummies indicate that relative contracted prices (as compared to maximum tariffs) decreased.

We have performed a number of specification tests for our model (Hausman test and the link test.) ${ }^{17}$ These tests accept our specification form. Also the proportion of censored data in the initial sample has appeared to be close to the proportion of censored data as predicted by the model.

\subsection{Controlling for Quality}

Although we find a positive relationship between price and market share (and insignificant relationship with $\mathrm{HHI}$ ), we cannot rule out that both differences in price and differences in market share are caused by differences in quality. For example, suppose health care purchasing agencies prefer to contract suppliers with high quality, and suppose also that it is costly to produce higher quality. Then this will result in a positive relationship between price and market share even if firms with high market share have no market power.

In order to further investigate this possibility we need to control for quality in our estimations. However, quality data are not available for the complete sample, but for a smaller sample of providers. Therefore, we can control for quality differences for this restricted sample of providers. This will allow us to check for sensitivity of the estimates obtained in regression 2 (see Table 2) to the inclusion of quality. Besides, it may give us some insights into the relationship between quality and prices, if the coefficient for quality appears significant.

In 2005, an independent research bureau conducted a survey among 55,000 clients of 82 Dutch home care providers. The participants of the survey were asked to evaluate their care providers on different aspects of quality on a scale from 0 to 10 . These evaluations were then aggregated to determine an integral quality score for each provider. ${ }^{18}$ Figure 4 shows a scatter of the available observations on quality and respective regional market shares of home care providers in 2005 . The discrepancy in the quality scores is not very large. The correlation coefficient between market share and quality is -0.40 , and highly significant ( $p=0.0034)$, casting doubts on the argument about a superior quality of larger providers (at least for this sample).

Table 2 (regressions 3 and 4) shows the results of regressions that control for quality differences. Both regressions include two variables to control

17 The former tests that the probit part and the truncated regression part have the same normalized coefficients, as implicitly assumed by Tobit; and the latter test checks the potential misspecification of the functional form of the model (Pregibon 1980).

18 These data are currently publicly available on the website http://www. kiesbeter.nl. 


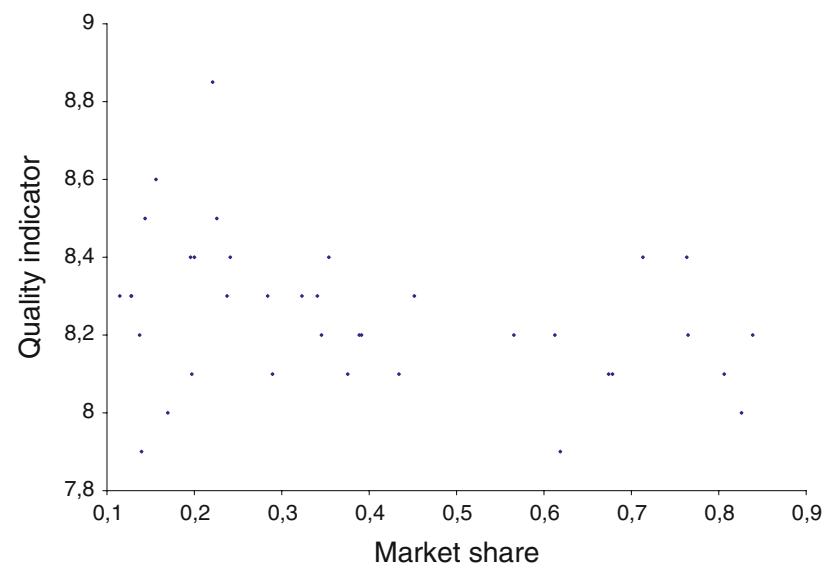

Figure 4 - Quality and market share (smaller sample, year 2005)

for quality: 'quality' (this is equal to the quality score if information is available, and 0 otherwise) and 'missing quality dummy' (equal to 1 if quality data is not available, and 0 otherwise). Furthermore, since quality data are available only for 2005, we first report the results including this year only (regression 3), then the results (regression 4) for the period 2004-2006, based on the assumption that quality (or strictly speaking quality differences) does not change over time.

The findings indicate that the relationship between market share and price remains after controlling for quality. The coefficient for quality is positive, but insignificant. This precludes firm statements about the effect of quality on prices.

\section{CONCLUSIONS AND POLICY IMPLICATIONS}

This paper evaluates the effect of market share on contracted prices of regional providers of home care in the Netherlands and explains the observed price differences across providers. We focus on two alternative explanations for these differences: provider market power and differences in quality. Both explanations are plausible: on the one hand, large providers may be able to exploit market power by raising prices above competitive levels; on the other hand, price differences across providers may be driven by quality, if health care purchasing agencies are willing to pay for better quality.

Our econometric analysis shows that, indeed, a larger market share is associated with a higher price. This supports the conjecture about higher market power of large home care providers. Note that this interpretation remains valid even if bigger firms would have higher costs (on which we do not have data), because in a competitive market, only firms of optimal scale would 
remain active. If large, high-cost firms are able to pass on their costs in prices, then (ceteris paribus) this is evidence of market power.

As said, there could have been a second explanation for this finding that is unrelated to market power. Suppose larger providers deliver higher quality. If purchasing agencies prefer to contract high quality providers, and if it is more costly to produce high quality, then this would also produce a positive correlation between market shares and price. Unfortunately, quality data are not available for the whole sample. Therefore, we can only check our hypothesis for a smaller sample. The findings indicate that the relationship between market share and price remains after controlling for quality. This suggests that market power, rather than quality, explains the observed price differences in home care.

How could policy measures countervail this market power? To answer this question, let us first discuss what makes large providers be so strong negotiators. As we explained in Section 3, health care purchasing agencies must fulfill strict obligations with respect to the amount of care contracted for covering the region's demand. However, they lack financial incentives to buy this care efficiently since they do not bear any financial risk on the price of care they purchase from providers, while they do carry full financial risk on the operational cost of contracting and negotiating. This may be a reason why they prefer to deal with a limited number of larger suppliers rather than with numerous small suppliers so that their transaction costs are kept down and their operation cost budget is not fully exploited. Another factor weakening the negotiation position of the purchasing agency vis-à-vis large providers is that not concluding a contract with these providers would cast a negative image on the agency represented by an insurer, presumably affecting the insurer's position in the market for health insurance. Therefore, health care providers know they will get a deal with the purchasing agency and have thus no incentives to reduce the price.

From a policy viewpoint there are two possible solutions focusing on different time horizons. In the short run, one can think of stronger financial incentives for purchasing agencies, or imposing more efficient procedures, such as auctions, to assign EMEA services to individuals. ${ }^{19}$ An auction mechanism stimulates competition between bidders and allows sellers and buyers to gain from the service exchange, provided that quality is clearly defined, contracted and enforced.

In the long run, an option may be that health insurers take over the responsibilities of the purchasing agencies in contracting with health care

19 Since 2005 for example online auctions on postpartum services are taking place in the Netherlands via an internet website. This auction takes place between health care insurers and providers of care. The auction works as follows: The request for postpartum services is placed on internet and subsequently care providers have seven days at disposal to auction off. 
providers. If health insurers are made to bear all financial risks associated with carrying out this task, then they will have an incentive to bargain for a low price, possibly using an auction scheme as outlined above. Moreover, health insurers operate on a larger regional scale than purchasing agencies. As a result, health insurers will have a stronger bargaining position. However, since insurers may appear to be more focused on prices than on quality in their choice of providers, the issue of quality may arise. It is possible that the market mechanism will safeguard quality, e.g. if consumers "vote with their feet" by switching insurers in case of low quality. However it is unclear whether this mechanism creates a credible threat, since consumers of home care may not be profitable for health insurers. In principle, a risk equalization scheme could be used to address the latter problem, but whether this is feasible in practice remains an open question.

\section{APPENDIX 1: FUNCTIONS OF LONG-TERM CARE}

The long-term health care services that are covered by the EMEA insurance is currently subdivided in 7 functions of care summarized in Table 4.

TABLE 4 - FUNCTIONS OF CARE

\begin{tabular}{|c|c|c|}
\hline & Function of care & Description \\
\hline 1. & House care & $\begin{array}{l}\text { Activities related to house keeping, such as cleaning } \\
\text { and tiding up }\end{array}$ \\
\hline 2. & Personal care & $\begin{array}{l}\text { Activities related to personal care such as help with } \\
\text { showering, dressing up, and help with eating and } \\
\text { drinking }\end{array}$ \\
\hline 3. & Nursing & $\begin{array}{l}\text { Medical care given to patients, namely injections, } \\
\text { wound care, and drug administration }\end{array}$ \\
\hline 4. & General supervision & $\begin{array}{l}\text { Activities aimed at enhancing the integration of the } \\
\text { individual into the society, e.g., support to plan daily } \\
\text { activities }\end{array}$ \\
\hline 5. & Activating supervision & $\begin{array}{l}\text { Activities related to recovering individuals from psy- } \\
\text { chological illnesses, e.g., how to change behavior in } \\
\text { the society }\end{array}$ \\
\hline 6. & Treatments & $\begin{array}{l}\text { Activities aimed at curing diseases, e.g., revalidation } \\
\text { after a stroke }\end{array}$ \\
\hline 7. & Residency & $\begin{array}{l}\text { This is residential care, when the patient needs to } \\
\text { be placed in an institution because home care help } \\
\text { would not suffice }\end{array}$ \\
\hline
\end{tabular}

Source: Decision on EMEA contracts, 25 October 2002. Besluit zorgaanspraken AWBZ, 25 oktober 2002, http://www.st-ab.nl/wetawbzorbza.htm. 
Open Access This article is distributed under the terms of the Creative Commons Attribution Noncommercial License which permits any noncommercial use, distribution, and reproduction in any medium, provided the original author(s) and source are credited.

\section{REFERENCES}

Bamezai, A., G. Melnick, J. Mann and J. Zwanziger (2003), 'Hospital Selective Contracting withoug Consumer Choice: What Can We Learn from Medi-Cal?'. Journal of Policy Analysis and Management, 22(1), pp. 65-84.

Brooks, J.M., A. Dor and H.S. Wong (1997), 'Hospital-Insurer Bargaining: an Empirical Evidence of Appendectomy Pricing'. Journal of Health Economics, 16, pp. 417-434.

Burr, J.A., N.G. Choi, J.E. Mutchler and F.G. Caro (2005), 'Caregiving and Volunteering: are Private and Public Helping Behaviors Linked?'. Journals of Gerontology, 60B(5), pp. S247S256.

CTG/ZAio and CTZ (2005), 'Visiedocument extramurale AWBZ-zorg', Analyse en aanbevelingen voor concurrentie, Utrecht.

Gal-Or, E. (1999), 'The Profitability of Vertical Mergers Between Hospitals and Physician Practices'. Journal of Health Economics, 18(5), pp. 623-654.

Halbersma, R.S., M.C. Mikkers, E. Motchenkova and I. Seinen (2007), 'Market Structure and Hospital-Insurer bargaining in the Netherlands', TILEC Discussion Paper DP2007-006.

ICM (Interdepartementale Commissie Marktordening) (2005), Tot zorg geprikkeld: arbeidsproductiviteit en innovatieve kracht in de zorg, The Ministry of Economic Affairs, October 2005.

McKnight, R. (2006), 'Home Care Reimbursement, Long-Term Care Utilization, and Health Outcomes'. Journal of Public Economics, 90 (1-2), pp. 293-323.

Melnick, G., J. Zwanziger, A. Bamezai and R. Pattison (1992), 'The Effects of Market Structure and Bargaining Position on Hospital Prices'. Journal of Health Economics, 11, pp. 217-233.

NMa (Nederlandse Mededingingsautoriteit) (2004), 'Visiedocument AWBZ-zorgmarkten', January 2004, The Hague.

NZa (Nederlandse Zorgautoriteit) (2006), 'Monitor extramurale AWBZ-zorg', June 2006, Utrecht.

NZa (Nederlandse Zorgautoriteit) (2007), 'Uitvoeringstoets: Overheveling zorgkantoortaken'. Voorstellen voor de korte en de lange termijn, March 2007, Utrecht.

Pregibon, D. (1980), 'Goodness of Link Tests for Generalized Linear Models'. Applied Statistics, 29, pp. $15-24$.

PWC (Price Waterhouse Coopers) (2005), 'Contractering AWBZ-zorg 2005', November 9, 2005.

Staten, M., W. Dunkelberg and J. Umbeck 1987, 'Market Share and the Illusion of Power'. Journal of Health Economics 6(1), pp. 43-58.

Staten, M., J. Umbeck and W. Dunkelberg (1988), 'Market Share/Market Power Revisited'. Journal of Health Economics 7(1), pp. 73-83.

Svejnar, J. (1986), 'Bargaining Power, Fear of Disagreement, and Wage Settlements: Theory and Evidence from US Industry'. Econometrica, 54(5), pp. 1055-1078.

van den Berg, B. and F.T. Schut (2003), 'Het Einde van Gratis Mantelzorg?'. Economisch Statistische Berichten, 88(4413), pp. 420-422.

WHO, World Health Organization (2003), 'Key policy issues in long-term care', Geneva: WHO. 
WHO, World Health Organization (2008), 'How can the settings used to provide care to older people be balanced?', Geneva: WHO. 